\title{
PERFORMANCE E MÚSICA: POSSIBILIDADES DE TROCAS AFETIVAS E DE OCUPAÇÃO DO ESPAÇO PÚBLICO NO FESTIVAL ATIVISTA DE FANFARRAS HONK! RIO 2018
}

- MICHEL MOREAUX*

Resumo 0 abjetivo deste estudo é a análise das possibilidades sonoras e afetivas oriundas de certas perfarmances de grupos de fanfarra que participaram da festival ativista de fanfarras Honk! Rio em 2018. Cabe questionar em qual medida issa participa de formas de ocupaçãa mais potentes do espaça público. Y faco deste trabalha são as performances que ocorreram durante a edição de 20l8. ( trabalho de campo, de cunho etnográfico, fai realizado durante a festival, com base em entrevistas com o pública, músicas, arganizadores e vendedares ambulantes, além de coleta de observações do campo e também se apresentanda em algumas acasiões. Inicialmente, será apresentada a trajetória da mavimenta Honk!, de Sommerville (Estadas Unidas) até o Rio de Janeira, relacionanda como a nação de performance se estabelece camo viés de análise deste estudo. Em seguida, serão abordadas aspectas das perfarmances que ocorreram no Honk! Rio, discutinda a experiência dos músicos participantes do festival. Par fim, serão retratadas duas perfarmances específicas, com o objetivo de expar as passibilidades oriundas da mistura de linguagens artísticas e da performance coma ato político.

Palavras-Chave: performance; espaço público; fanfarras.

\section{Introdução}

Esse trabalho surge através do meu envolvimento inicial, como músico, em algumas fanfarras e coletivos do Rio de
Janeiro, que acabaram contribuindo e participando da construção do festival ativista de fanfarras Honk! Rio, cuja primeira edição ocorreu em 2015. Apesar de ter participado em todas as edições, o 
trabalho de campo foi realizado aconteceu durante a preparação e a realização da edição 2018 deste festival, em parceria com a antropóloga Maria Claudia Pitrez, que também participa de fanfarras no Rio de Janeiro. A partir das práticas concretas, relacionadas ao fato de tocar música na rua, as fanfarras, este trabalho busca aprofundar elementos oferecidos pela Antropologia da música e dos sons (Pinto, 2001; Menezes, 2007), e contribuir para uma ampliação do diálogo entre saberes dentro da Geografia (Dozena, 2017; Bartholl, 2018).

Neste artigo, destaca-se a noção de performance, a fim de explorar certas possibilidades de estudo da dimensão sonora na Geografia, tal como preliminarmente esboçado em artigo publicado recentemente (Moreaux, 2018). Será situada a apropriação deste conceito no escopo do artigo, destacando as inspirações oriundas do campo da Antropologia da performance, que ressaltam a dimensão da experiência (Turner, 1987; Hikiji, 2007; Pinto, 2001). Deve-se sublinhar que essa noção leva a considerar a dimensão da corporeidade, que "se revela enquanto oportunidade de criação de redes de convivência e de solidariedade, traduzindo-se como núcleo primeiro de sociabilidade” (Dozena, 2017. p.372).
Esta investigação explora como este tipo de encontro presencial, entre participantes de fanfarras oriundas de cidades e países diferentes, permite um diálogo entre fanfarras, que se desdobra num aprimoramento do lado performático das suas apresentações. A hipótese levantada sugere que o festival potencializa a ocupação efetiva e afetiva do espaço público, na cidade do Rio de Janeiro. Algumas perguntas guiaram este estudo: a construção do festival proporciona um diálogo entre as fanfarras, que estimula o desenvolvimento das performances das fanfarras? $O$ que os participantes das fanfarras pensam acerca da performance, e como eles retratam sua vivência e seu engajamento no Honk! Rio? Como isso se desdobra nas possibilidades concretas de ocupação afetiva e sonora desse tipo de festival?

\section{Criação do festival HonkFest em Sommerville, nos Estados Unidos}

O primeiro festival de tipo "Honk!", o Honk! festival of activist street bands de Somerville, em Massachusetts (Boston/EUA), surgiu no ano de 2006, como um festival de música de rua para provocar uma ruptura do cotidiano e chamar atenção (o termo "Honk' diz respeito ao som de buzinas de carros). $\mathrm{O}$ 
festival é sem fins lucrativos e foi criado nessa perspectiva de ativismo social, para ampliar a conexão das pessoas entre si e com o espaço público ao redor, através de apresentações de bandas. Seus três 3 dias de duração visam levar uma nova vida para o cotidiano das ruas e fortalecer os vínculos comunitários, pois envolve pessoas de todas as idades, moradores, visitantes e comerciantes, como participantes e apoiadores do evento. Segundo a descrição na sua página internet, o festival "Honkfest" almeja "recuperar o espaço público com som”.

Este festival vai completar em 2019 sua $13^{\text {a }}$ edição. Sua fama se expandiu por outros locais, dentro e fora dos Estados Unidos $^{1}$. A ocupação e transformação espacial da cidade é uma preocupação marcante dos festivais Honk. As trocas entre fanfarras de diferentes lugares, que circula entre os festivais, tende a gerar uma rede de solidariedades, com potencial de ação que afeta os lugares investidos no tempo de duração de cada festival. Coletivamente, inventam-se formas de organização para viabilizar tais festivais (hospedagem solidária, logística...), assim como novas formas de trocas afetivas durante os momentos de apresentação dos grupos, para um público mais amplo. É interessante pensar como este "padrão Honk" veio a se estabelecer nos diversos lugares onde foi implementado, a partir do estabelecimento de algumas premissas, quanto ao caráter voluntário ou sem fins lucrativos do festival, mas também realçando as diferenças e singularidades em cada lugar e sua cultura própria.

\section{Honk! Rio: um festival que fortalece a proliferação de um certo movimento de} fanfarras na cidade

No caso da expansão do Honk! no Brasil, o início da troca ocorreu em 2013, com a participação da fanfarra carioca "Os Siderais", no Honk de Somerville. Os membros deste grupo de fanfarra carioca, que também era considerado um grupo ativo junto aos movimentos sociais brasileiros no ano de 2013, ficaram impressionados pelo acolhimento na casa de moradores da cidade, o carinho por parte dos organizadores e pela organização e o formato do festival. Inspirados por esta experiência, amadureceu-se a ideia de criar um festival do mesmo no Rio de Janeiro, que ocorreu efetivamente em $2015^{2}$.

No universo "Honk!", o festival que acontece no Rio de Janeiro tem a característica de trazer fanfarras "locais", da cidade do Rio de Janeiro ${ }^{3}$. Isso se deve, sem dúvida, pela importância que o Carnaval de rua no centro do Rio de Janeiro tomou a partir da virada dos anos 
2000 (Herschmann, 2013; Frydberg, 2017).

A grande maioria das fanfarras cariocas, que atuam no Honk! Rio, participam de alguma maneira do carnaval: formando bloco próprio, oficinas de musicalização, ou simplesmente desenvolvendo um cortejo com amigos ou outros músicos de outras fanfarras, logo antes, ou durante o Carnaval. O desfile da Orquestra Voadora, que adquire inicialmente uma importância primordial na estruturação desse movimento do "neo-fanfarrismo" carioca (Snyder, 2018)4, era composta, no desfile de 2018, por 500 pessoas, entre estas músicos, pernaltas, circenses e staff. A multidão que cercou este desfile, na terça-feira de carnaval, foi estimada em cem mil pessoas.

Inúmeros blocos emblemáticos da área central da cidade do Rio de Janeiro foram homenageados ao longo das quatro edições do festival. Porém, os grandes blocos associados às fanfarras que participam do Honk! Rio acabam tocando sobretudo em formato de banda, isto é, um formato reduzido de integrantes na banda, diferente da composição que origina os blocos associados. Isso decorre em parte da própria escolha programática da organização do festival, mas também pela dificuldade logística de deslocamento intermunicipal. A organização do festival, coletiva e de caráter voluntária, ao longo dos anos, foi definindo um modus operandi e um ethos próprio ao Honk! Rio. A fala de uma das organizadoras do Honk! Rio, por exemplo, sugere uma preocupação com uma distinção do festival com o carnaval:

Esse movimento de fanfarra, que é bem próximo e surgiu coligado ao carnaval, traz um desafio que é o de distanciar o festival de determinados estereótipos e comportamentos que o carnaval instaura, de loucura total e subversão das regras! Será que toda intervenção na rua de música tem que se transformar num carnaval? É um pensamento que a gente tem e que tentamos ver o jeito de desvencilhar de algumas loucuras total e pensar no espaço, na limpeza, nas pessoas que vão assistir e como podemos manter um vínculo o ano todo com esses locais. (L., organizadora)

Essa fala não é isolada. Foi encontrada em outras falas de músicos ou até de pessoas do público. Denota esta vontade compartilhada de construir, aos poucos, uma verdadeira proposta de festival ativista, seguindo as premissas do Honk! Sommerville, com destaque as preocupações sociais e políticas 5 .

A programação do Honk! Rio 2018 foi densa e extensa: 65 apresentações agendadas ao longo dos cinco dias de programação, realizadas por trinta fanfarras diferentes; cinco cortejos 
envolvendo 9 fanfarras; cinco oficinas (palhaçaria aplicada à fanfarra e dinâmicas de composição coletiva); uma sessão de três rodas de conversa. O formato da edição 2018 do festival privilegiou a troca entre os grupos. Além de fomentar uma noite de debate, no primeiro dia do festival, acerca de temáticas contemporâneas, como feminismo e sobre o papel e a segurança das redes sociais, também com espaço para oficinas (acerca da musicalidade e em conjunto com palhaços) e uma noite de confraternização entre os músicos participantes do festival. Destacaram-se também as "batalhas de fanfarras" na programação, onde uma se apresenta revezando com outra, assim como cortejos onde mais de uma fanfarra participam enquanto perambulam pelas ruas, inclusive em momentos após a programação, quando os músicos perambulam e tocam até o sol raiar.

Constata-se que existem inúmeros momentos de trocas de saberes entre as diversas fanfarras. Há muita troca de informação acerca do repertório, das formas de interação, os modos de se organizar, de atuar frente ao público. Neste trabalho, mostrou-se interessante a dimensão da performance, tal como ela é experienciada e discutida, principalmente pelos músicos. Antes de explorar suas contribuições, faz-se fundamental a apresentação da noção de performance.

\section{Noção de performance como possível viés de análise do festival Honk! Rio 2018}

A noção de performance ganhou força em estudos antropológicos e geográficos. Como ressalta o antropólogo Tiago Pinto (2001, p.229), "performances marcariam todas as atividades humanas, sempre que inseridas em algum quadro de referência sociocultural". Por sua vez, o geógrafo Daniel Paiva (2017), ressalta que a performance se torna uma palavra-chave, em particular, nos estudos oriundos das teorias não-representacionais:

As teorias não-representacionais vêm contestar essa divisão, afirmando que o conhecimento não é divisível da realidade no qual emerge, contrariando a clássica divisão cartesiana entre representação e realidade, entre mente e corpo. Neste sentido, a produção de conhecimento passa a preocupar -se não apenas com as representações mentais da realidade (e.g. significados, sentimentos, discursos, estruturas), mas também com o modo como essas representações são produzidas e praticadas

corporeamentecorporalmente no decorrer das ações e interações de que o mundo é constituído ( práticas, 
hábitos, afetos). A performance tornase assim uma palavra-chave. (Paiva, 2017, p. 161)

Portanto, cabe delinear um pouco melhor o que abrange a noção de performance, neste estudo acerca do festival Honk! Rio. A noção de performance musical veio inicialmente à tona nos estudos de etnomusicologia, antes de sua apropriação nas reflexões dos antropólogos (Pinto, 2001). Ao realizar uma densa apresentação dos campos de interesse da Antropologia da Música e do Som, Pinto enumera os "signos" da performance:

Ao lado dos signos visuais, como a decoração e a organização do espaço, há os elementos acústicos, como a música e outros tipos de sons. Além destes devem ser considerados texto e enredo da performance, com seus significados lexicais, sintáticos e simbólicos. Os produtores e protagonistas da performance dependem dessa soma de elementos, que constituem o plano sensório e de convenção geral. Em conjunto com os elementos da dramaturgia temos aí matéria-prima com a qual se constroi outras grandezas, ou seja, através da sua performance o acontecimento sonoro da música traz à tona fenômenos diversos, por vezes inesperados, e não necessariamente acústicos (Pinto, 2001, p.229)
A antropóloga Rose Hikiji (2005), ao realizar uma etnografia da performance sobre a atuação do projeto pedagógico e musical Guri, ressalta a performance como “espaço de transformação”, apoiando-se na apropriação, por Richard Schechner (2002), dos estudos pioneiros acerca da performance do antropólogo Vitor Turner (1987):

As transformações via performance se dão tanto nos performers (que rearranjam seu corpo e mente) como no público. Nesse, as mudanças podem ser temporárias (e aqui se está falando da performance como entretenimento) ou permanentes (no caso do ritual) (Hijiki, 2005, p.159).

Ao longo do trabalho de campo, junto com a colega Maria Claudia Pitrez, focalizou-se tanto aos performers propriamente ditos, isto é, os músicos participantes do festival Honk! Rio, como também os participantes, o público do evento. Durante este processo, observamos muitas apresentações e participamos de algumas ocasiões. Foram entrevistadas várias pessoas do público, assim como músicos, particularmente sobre a noção de performance ${ }^{6}$. Antes de adentrar a síntese desses relatos, vale ressaltar como se pode perceber a atuação e recepção da performance no espaço público. Neste aspecto, a contribuição de Stavrides (2016) 
é relevante ao questionar como o espaço da cidade pode expressar e fomentar práticas e valores distintos, ou até opostos, aos valores dominantes. $\mathrm{O}$ autor ressalta que:

O que está aqui em jogo não é exatamente o uso real ou potencial de determinadas configurações físicas existentes, senão como se geram e que formas adquirem os espaços através de práticas e modos de habitar e de perspectivas compartilhadas (por exemplo, a memória e os sonhos coletivos) (Stavrides, 2016, p.31).

A perspectiva militante do festival Honk! Rio sugere se adequar com esse tipo de questionamento. $\mathrm{O}$ acontecimento em si do festival é relativamente breve, pois dura cinco dias, mas mobiliza seus participantes diretos (os músicos, outros artistas e pessoas próximas) durante meses, e no caso dos organizadores durante o ano todo. Sobretudo, constatam-se marcas registradas no imaginário coletivo, que podem ser atribuídas à forma coletiva de ocupar diversos lugares da cidade, através de performances e espetáculos.

A diversidade das abordagens das performances foi um destaque na edição 2018. Cabe destacar que participei de " $\mathrm{x}$ " edições do Festival Honk! Rio, ao longo das quais observei que a dimensão performática da música estava sempre mais levada em conta pelos músicos. A imersão no Honk! Rio parece catalizar uma emulação elaboração das apresentações, através de trocas de linguagens e de saberes entre as fanfarras. A seguir, serão apresentadas observações realizadas durante a vivência no festival, apoiando-se sobreas entrevistas e questionários, que foram respondidos por 75 músicos participantes das fanfarras do Honk! 2018.

\section{Acerca da performance: síntese das observações, vivências e das entrevistas realizadas durante o Honk! Rio 2018}

\section{Repertório eclético das diversas fanfarras envolvidas}

Ao falar de performance musical é importante evocar o repertório e certas sonoridades que animaram o público durante o festival Honk! Rio, em 2018. Nesta apresentação será tratada a diversidade de propostas artísticas que permeou o festival.

Cada fanfarra acaba realizando um trabalho específico acerca dos timbres e, cada vez mais, observa-se a diversidade das sonoridades, que passa por trabalhos de arranjo musical, mas também de movimentação corporal, ao longo das apresentações se destacam por trabalhos de arranjos musicais que surpreendem pelos timbres. Um exemplo deste trabalho se destacou no protagonismo de três fanfarras 
brasileiras (Calango Careta (DF), Sagrada Profana (MG), Sanfônica ambulante (RJ), que se destacavam por seu uso de flautas dentro da sua formação, que ganhavam protagonismo através dos arranjos. A Fanfarrada (RJ) explora a diversidade dos ritmos da América latina, introduzindo outras percussões, além dos tradicionais surdos e caixas que a maioria das fanfarras emprega. A banda Bagunço, da qual participo, incorpora uma guitarra e um keytar, instrumentos pouco usados no meio das fanfarras e que precisam ser amplificados, mas que agregam outra sonoridade e outras possibilidades de arranjo para o conjunto.. As duas fanfarras francesas presentes nesta edição, constituídas por músicos amadores, contudo experientes em fanfarra, chamou atenção por seus timbres: a fanfarra 3615 Brass band tocava um repertório "internacional", com arranjos poderosos para o seu segmento. Quanto à fanfarra exclusivamente feminina Les Muses Tanguent, a presença de cinco bombardinos se destacou pelas possibilidades sonoras que foram exploradas, as quais não são comuns entre as fanfarras brasileiras que participam do Honk! Rio.

O repertório tocado por essa diversidade de fanfarras é dos mais ecléticos: são tocados covers do mais diversos gêneros musicais (MPB, internacional, rock, música latina, black music, canções feministas, etc.), assim como a presença frequente de repertório autoral. As fanfarras vindas de fora se deparam como uma grande combinação de ritmos de diversas matrizes: há essa variedade rítmica que provém das diversas bases rítmicas das culturas populares do Brasil (samba, maracatu, coco, xote, congadas, marchinhas, jongo, toques de candomblé, funk, dentre outros). Isso tudo se combina com vários outros ritmos do repertório mundial (New-Orleans, balcânico, rock, swing, cumbia, salsa, etc.). As fanfarras usam esta variedade rítmica como um recurso para os arranjos dos covers que realizam ou que combinam dentro das suas composições próprias.

Disso decorrem múltiplas possibilidades de dançar, para múltiplos gostos, o que sugere um diferencial que poderia explicar em parte o sucesso do Honk! Rio para um público muito abrangente. Aos poucos, desvincula-se a proposta sonora do Honk! Rio com àquela tradicional do Carnaval de rua do Rio de Janeiro, como fora mencionado por numerosa parte do público que costuma seguir os blocos associados com as fanfarras cariocas. Experiencia-se melhor, em suma, as sonoridades que provém das formações reduzidas das fanfarras, quando 
de forma distinta daquela dos blocos do carnaval de rua.

\section{Dimensão corporal do ato de tocar e de ouvir}

Muitas entrevistas ressaltaram esse prazer de tocar e de ouvir entre os participantes de todos os tipos, destacando, muitas vezes, essa dimensão corporal do ato de tocar (e ouvir). Esta dimensão ecoa em certas indagações do geógrafo inglês Gallagher, (2016, p.2), notadamente quando este destaca o envolvimento dos corpos na dimensão sonora, ao considerar o movimento vibracional dos diversos corpos envolvidos.

Certos músicos ressaltaram a experiência de sentiras vibrações ao tocar seu instrumento, seja o de sopro ou percussão, e essa vibração interior se mistura com as vibrações do conjunto de músicos, em interação com a acústica do lugar e com o público. Quanto ao público, este aprecia as músicas tocadas e a performance, entretanto as pessoas destacam, por exemplo, o prazer de ouvir o timbre de instrumentos que nem todo mundo costuma ver e sentir ao vivo no diaa-dia. Da mesma maneira, vendedores ambulantes de rua são vistos dançando, ou ainda batendo o ritmo da música em seu equipamento de trabalho. Muitas conversas e entrevistas evocam esse contágio da dimensão sonora nos corpos humanos, durante esses cinco dias de programação.

Traz principalmente prazer em tocar. E esse prazer parece contagiar todos os envolvidos, tanto músicos como ouvintes. (M. trombonista)

A apresentação do segundo dia foi especial, porque tivemos mais espaço pra tocar e ficamos mais próximos do público. A ressonância para os instrumentos melhora, quando se tem mais espaço, especialmente para as flautas. Também a turma toda consegue dançar. Nossa performance melhora de modo geral. (L., Flautista) (...) você quer saber o que mais conta pra mim? Quando eu vejo um morador de rua se divertindo e interagindo com a música, quando vem me perguntar "que instrumento é esse que eles estão tocando", quando eu vejo uma criança imitando um sax ou um trompete. Isso é o que mais me dá prazer em participar desse evento. (A, trombonista)

Essa possibilidade de afetar outras pessoas através da performance musical é considerada uma dimensão importante para muitos dos participantes.

Cabe mencionar também os momentos de comunhão entre músicos que se estendem após a programação "oficial" do Honk! Rio. O festival visa respeitar o toque de recolher nos lugares onde tem 
moradias, mas há momentos do festival que se estendem pela noite, em lugares apropriados. Muitos músicos esperam o final da programação para poder tocar de maneira improvisada entre si, compartilhando repertório em comum, ou seguindo quem propõe músicas. As fanfarras que vêm de fora destacam muito essa possibilidade de tocar sem parar que vigora no meio das fanfarras do Rio de Janeiro, o que fomenta laços afetivos e musicais entre os participantes. Isso participa também do cansaço progressivo dos participantes ativos do festival, que acabam ficando num estado de efervescência singular, decorrente do cansaço, notadamente no último dia.

$\mathrm{O}$ viés performático acaba se tornando um destaque dessa modalidade de apresentação no espaço público. Porém, significa mais que o mero repertório escolhido pelas fanfarras, ou ainda a execução musical: envolve as modalidades da interação entre todos os participantes destas apresentações e cortejos.

\section{Valorização do lado performático das} apresentações por parte dos músicos

As fanfarras andam pensando e melhorando coreografias, figurinos, dinâmicas das músicas e arranjos. Algumas chegam a acrescentar elementos circenses. Em diálogo com os músicos, ao perguntar se eles consideram que a execução de performance modifica a troca e relação entre música, músicos e público, e porque, foram recolhidas inúmeras contribuições, que testemunha a vivacidade desta pesquisa na grande maioria das fanfarras envolvidas no Honk! Rio:

$$
\begin{aligned}
& \text { Costumamos estrear repertório só, } \\
& \text { mas depois deste festival estamos } \\
& \text { discutindo a inclusão de novas } \\
& \text { linguagens artísticas nas nossas } \\
& \text { apresentações. (T., percussionista) } \\
& \text { O lance de tocar na rua é o encontro } \\
& \text { que acontece naquele momento. E } \\
& \text { performance é tudo. Ultrapassa a } \\
& \text { expressão musical. (D., trombonista) } \\
& \text { Sim. A parede entre artistas e público } \\
& \text { deve ser quebrada. Todos são parte do } \\
& \text { espetáculo. (A., caixa) } \\
& \text { É preciso se conectar com as pessoas } \\
& \text { pra que essa troca seja completa. A } \\
& \text { música não se resume às ondas sonoras } \\
& \text { que chegam nos ouvidos do público, } \\
& \text { mas envolve todas as experiências que } \\
& \text { constroem o show. (C., trompetista) } \\
& \text { Sim, acho que aumenta a atenção do } \\
& \text { público e a interação com a banda, e } \\
& \text { dependendo da performance, resulta } \\
& \text { em arrebatamento coletivo. Acho que } \\
& \text { toda banda busca algo assim, e o } \\
& \text { público também espera encontrar essa } \\
& \text { catarse em algum momento. Quando } \\
& \text { rola, quase sempre é mágico. (M., surdo) }
\end{aligned}
$$


Denota-se a vontade de "quebrar a parede" entre os músicos e o público, integrar todo mundo na performance musical. Os adereços constituem uma primeira forma de caracterização. Porém, este envolvimento se opera, antes de mais nada, pela movimentação dos corpos: pela dança, pelas coreografias e pelas brincadeiras. Verifica-se esta preocupação, que realça uma vontade de alcançar uma comunhão entre os músicos e os outros participantes. O festival se configura com este foco no espaço de troca, onde os músicos encontram inspirações e ideias para implementar durante o ano, para afetar e comungar da maneira mais potente com seus respectivos públicos.

A seguir, será explorada a maneira segundo a qual muitas fanfarras misturam o ato de tocar com outras linguagens artísticas, das quais podem ser destacadas: o universo circense, de um lado, e o canto e a dança, de outro. No contex to deste artigo, separo estes dois aspectos, pois são representativos deste diálogo entre linguagens que tomou lugar nas apresentações das fanfarras no Honk! Rio, caracterizando esta ampliação das possibilidades nas performances proporcionadas pelas fanfarras.
Incorporação das artes circenses, como possível ampliação da ressonância afetiva das performances das fanfarras no Honk! Rio

Essa incorporação de novas linguagens nas apresentações de muitas fanfarras é um viés interessante para abordar nessa edição do festival. Em particular, existe uma troca crescente de linguagens entre o universo das fanfarras e o universo circense. Alguns grupos de fanfarras que participam do Honk! vêm trabalhando isso. Por exemplo, é comum encontrar pessoas em cima de pernas de pau que dançam e fazem parte do show de várias fanfarras, como Trombetas Cósmicas, Calango Careta, quando não são os próprios músicos que tocam acima de pernas de pau, como no caso da Orquestra Voadora, que fomentou muito essa forma de interação das fanfarras através do seu cortejo de carnaval, que envolve cerca de cinquenta pernas de pau em algumas apresentações. Ficou nítido também a integração de números circenses dentro da performance de algumas fanfarras, que seja no Circo Sideral, com o cuspidor de fogo e acrobatas, na fanfarra mineira Sagrada Profana, com o número de bambolê e correias de fogo.

Destacou-se nesta abordagem a apresentação do espetáculo "Bagunço no Ato", que combina um coletivo de sete acrobatas circenses e os nove membros da banda Bagunço, reunindo 16 artistas. Esta 
apresentação, que ocorreu nos primeiros momentos do dia da abertura, foi considerada um momento marcante do festival, pois foi a primeira vez que estreou no Honk! Rio um espetáculo que mistura integralmente esses dois tipos de linguagens, que são o circo e a fanfarra, combinados através de uma trama dramatúrgica e trabalho coreográfico. $\mathrm{O}$ retorno dado pelo público e pelos outros músicos participantes do festival foi positivo: a união dessas duas modalidades amplifica, sem dúvida, a performance como um todo. Trata-se de algo mais espetacular, que permite ao mesmo tempo emocionar e interagir de maneira diferente. A terceira altura, que alcançam os acrobatas, cria uma impressão singular na plateia, ainda mais com os músicos acompanhando ao vivo ao redor.

Todas que eu vi tinham uma identidade muito própria e poderia ser citado. Mas destaco o Bagunço no Ato. Pela integração das linguagens artísticas, fazendo um espetáculo coletivo onde dança, circo e música dialogam diretamente, músicos e atores contracenam, é bem inovador. (B., público)

A fala repercute a dimensão da performance na apresentação, pois tratavase mais de um espetáculo do que um show musical. O público se aglomerou ao redor de todo o espaço cênico e muitas pessoas ficaram sentadas na arquibancada formada pela escadaria na frente da Câmara dos Vereadores. Essa modalidade de espetáculo também é desenvolvida por outras fanfarras, ou bandas que tem dentro da sua formação algumas pessoas que trabalham no universo circense, como, por exemplo, a apresentação dos Unidos do Swing.

A abertura do Honk! São Paulo também contou com uma parceria deste tipo entre fanfarra e circo, o que sugere que esta é uma maneira de potencializar a ocupação do espaço público, proporcionando outras intensidades e agregando um público ainda maior ao redor deste universo das fanfarras. Denotase também uma certa aproximação entre artistas de rua e/ou circenses e músicos de fanfarras. No Honk! Rio, a passagem de chapéu foi realizada por palhaços que tocam ou simpatizam com o festival, realizando com irreverência o pedido de “contribuição consciente", necessária para assegurar a organização de um festival que não busca patrocínio ou verba pública, mas que desse sustenta com um mínimo de recursos. Rodas de palhaços agregaram também pela primeira vez a programação do Honk! Rio.

A arte circense traz um universo e uma linguagem que permitem novas 
formas de impactar o público. A seguir, cabe relatar performances de uma fanfarra que chegam a integraresta linguagem circense, mas vai pensando o conjuto da performance com um viés ainda mais político.

Performance com viés mais político: o exemplo da fanfarra mineira Sagrada Profana

O contexto político e social do Rio de Janeiro e do Brasil, que antecedeu o festival, foi marcado pela eleição presidencial, que influenciou a maneira como os organizadores e os participantes encararam a ocupação efetiva dos lugares ocupados pelo festival. $\mathrm{Na}$ abertura do festival, na Praça Cinelândia, na escada da Câmara dos vereadores no Rio de Janeiro, muitas mulheres musicistas, participando das fanfarras do festival, se juntaram para formar a "Bloka", um bloco constituído por 60 mulheres. Este foi um dos momentos mais emocionantes e impactantes do festival, responsável por aflorar muitas emoções e demonstrações de afeto $^{7}$.

A fanfarra mineira Sagrada Profana, autodefinida como uma fanfarra feminina, também chamou a atenção. Segundo uma descrição presente na sua rede social, "surge como um espaço de encontro, criação, empoderamento e voz para as mulheres." O grupo desenvolve um trabalho próprio em Belo Horizonte, com um bloco de carnaval mais numeroso. No Rio de Janeiro, se apresentaram em um formato reduzido para a modalidade de fanfarra ${ }^{8}$.

A sua performance se destacou pois combinava muitos elementos: intervenção de uma artista circense de bambolê, que também manuseava bolas de fogo; o figurino de todas as dez integrantes era bem aparelhado entre si, dando uma coerência e identidade visual, com tons roxo e cinza brilhante. A formação não contava com tuba, o que é raro para fanfarras, porém o trabalho sobre os timbres e a fineza dos arranjos conseguia harmonizar muito bem o som das flautas e dos clarinetes. Além disso, o repertório foi cuidadosamente escolhido, constituído predominantemente por músicas compostas por mulheres ${ }^{9}$. Em vários momentos, as mulheres cantaram em coro letras de música, tanto letras originais, quanto letras reformuladas acima de uma música preexistente. As letras abordavam vários temas relacionados com a luta por direitos das mulheres, denunciando, por exemplo: o machismo, a proibição legal do aborto, ou ainda trazendo questionamentos sobre o controle e regras heteronormativas ao corpo feminino. Emanava da apresentação muita coragem e dedicação, consagrada por retornos positivos por parte do público e dos outros músicos. 
Eu e minha colega Maria Claudia Pitrez testemunhamos, em dois lugares diferentes, a empolgação de uma senhora de 80 anos por esta fanfarra feminina. $\mathrm{Na}$ sexta-feira, a Sagrada Profana atuou na Praça Saens Peña, e esta senhora estava passando. Adorou a performance, ficou emocionada e foi na sua casa para chamar sua irmã e voltou a assistir outras fanfarras naquele dia. Informou-se sobre o festival e a próxima apresentação desta fanfarra mineira, que ocorreu no dia seguinte, na Praça Paris, a mesma esteve presente e levou sua irmã e marido. Ela confessou ter ficado muito impressionada: "Gostei muito dessas meninas, da interação com o público, o repertório, o figurino, a execução musical e coreografias. Elas têm uma garra e suavidade, estão seguras ao tocar. E me emocionei muito quando gritaram 'Marielle Presente', porque foi minha vereadora".

\section{Considerações finais}

A construção do festival Honk! Rio como proposta de "festival ativista de fanfarra" foi constituída por um processo que se fortaleceu ao longo das suas quatro edições. Tendo vivenciado a criação do Honk! Rio em 2015, e participado de festivais Honk! nos Estados Unidos, o etnomusicólogo Snyder define o processo desta construção como uma forma dialógica de ativismo, construída dinamicamente por seus participantes (Snyder, 2018, p.236).

Este artigo focaliza a dimensão da performance, para demonstrar que a música constitui apenas um elemento das apresentações que são realizadas por este segmento. Os músicos participantes se enriquecem pelo contato com outros grupos e juntos fortalecem essa proposta de ocupação performática do espaço público. Em geral, os testemunhos relataram o quanto estes momentos se tornaram significativos para quem os vivenciou, como na fala: "Sentimento de comunidade. Ver um festival que é construído a mãos de tantas pessoas e que só acontece devido a cada mão, me traz uma sensação de que se nos engajarmos na construção de comunidades poderemos mudar significativamente a situação social”.

Observou-se como a intensidade das performances, a diversidade de linguagens e abordagens, apenas no campo de atuação de fanfarras, configura uma vontade coletiva de modificação das lógicas que guiam a organização programada do cotidiano. Esta tentativa de apresentar sinteticamente a diversidade das performances musicais, que compuseram a edição 2018 do Honk! Rio, deve ser enxergada como apenas mais um 
componente de pesquisas mais amplas acerca deste tipo de ocupação do espaço público por propostas artísticas, que não deixam de se atentar sempre mais com as dinâmicas dos lugares, buscando encarnar novas formas de organização que possam ecoar além deste tempo singular de um festival.

\section{NOTAS}

* Mestre em Geografia pela PUC-Rio. Doutorando do Programa de Pós-Graduação em Geografia na Universidade do Estado do Rio de Janeiro. Bolsista da Fundação Capes.

1 O festival acontece atualmente em Seattle, no Estado de Washington; em Austin, no Texas; Providence, no Estado de Rhode Island; na cidade de New York; em Eugene, Oregon; Montpelier, Vermont; Spokane, Washington; em Wollongong, na Austrália; no Rio de Janeiro (criado em 2015), São Paulo (criado em 2017), Brasília (criado em 2018) e Porto Alegre e Belo Horizonte (criados em 2019) no Brasil; e em Vancouver, no Canadá (criado em 2018).

${ }^{2}$ Ao longo das quatro edições do Honk! Rio, vieram fanfarras da Alemanha, da França, da Itália, do Chile, da Costa Rica, da Argentina e dos Estados Unidos. Ao mesmo tempo, o movimento Honk! se estruturou relativamente rápido no Brasil, através das trocas ocorridas com fanfarras de outras grandes cidades brasileiras (São Paulo, Belo Horizonte, Brasília, Porto Alegre, Niteroi e outras). As fanfarras de São Paulo costumam ser presentes no Honk! Rio (em 2018, haviam 4 fanfarras paulistas), as quais criaram o Honk! São Paulo em 2017, que costuma acontecer na semana seguinte ao Honk! Rio. A fanfarra brasiliense "Calango Careta" veio em três edições consecutivas do Honk! Rio e, junto com outras fanfarras locais, realizaram o Honk! Brasília em 2018. Por fim, houve pela primeira vez o Honk! PoA, em Porto Alegre, em abril 2019.

${ }^{3} \mathrm{O}$ primeiro Honk! Rio contou com a participação de 16 fanfarras cariocas. Em 2019, pela primeira foi necessário limitar a participação das fanfarras cariocas, sendo que, mesmo assim, haviam 21 fanfarras do Rio de Janeiro.

4 Ao retomar a expressão "neo-fanfarrismo" carioca, que é usada por certos participantes do Honk! Rio, Snyder (2018) explica como, no Rio de Janeiro, grande parte das fanfarras que participam do festival eclodiram no rastro da Orquestra Voadora (Snyder, 2018). Essa banda, famosa por seu bloco, constituiu um marco dentro do carnaval de rua carioca, por sua aposta na mistura de repertório. Muitos dos músicos cariocas que tocam no festival também participaram dos ensaios do seu bloco em algum momento da sua trajetória.

${ }_{5}$ Muito importante ressaltar que se trata de um processo. A construção deste ativismo por parte do festival se faz aos poucos, precisando inclusive ser construindo ao longo do ano todo. Não se trata aqui de aprofundar isso, mas há uma tendência de fundo, por parte dos organizadores, de trabalhar de maneira sempre mais organizada e coletiva esta questão, inserindo notadamente as outras fanfarras locais e seus integrantes nesta dinâmica. Segundo as mais recentes orientações da organização do Honk! Rio, esta tendência de fortalecer as relações com projetos culturais e sociais pela cidade deve se acentuar para a edição 2019, já que os organizadores apelam para as fanfarras cariocas explicitamente tecerem parcerias com projetos socio-culturais, esboçando uma teia de parcerias que poderia se tornar perene e orientar o encaminhamento do Honk! ao longo do ano. 
${ }^{6}$ Foram recolhidos 75 questionários de músicos e 55 de pessoas do público, de maneira presencial, durante o festival, ou por contribuição voluntária destas pessoas através da internet; além de outras conversas informais, e as anotações de campo durante a etnografia realizada.

${ }^{7}$ Pretendo deixar a análise deste momento para os trabalhos realizados por minha colega Maria Claudia Pitrez, ou ainda teve certo desenvolvimento no artigo que escrevemos em conjunto, em parceria com um site editado por pesquisadores norteamericanos, acerca do movimento "Honk!" pelo mundo:

http://www.honkrenaissance.net/moreauxpitrez.h tml

8 Interessante notar, nesta dinâmica de troca entre fanfarras do movimento Honk!, que a Sagrada Profana foi selecionada para a edição 2019 do Honk! Sommerville.

9 Há, por exemplo, músicas das norte-americanas Nina Simone e Madonna, mas também da brasileira Chiquinha Gonzaga, ou ainda de artistas contemporâneas, como Jhê Delacroix ou a chilena Claudia Manzo. Algumas vozes masculinas são contempladas, que falam de mulheres, como "Maria Maria”, do Milton Nascimento, “Odára”, do Caeteano Veloso, ou ainda "Nanã" do Moacir Santos, e “Geni e o Zepelim”, de Chico Buarque.

\section{REFERÊNCIAS BIBLIOGRÁFICAS}

BARTHOLL, T. (2018). Por uma geografia em movimento. A ciência como ferramenta de luta. Rio de Janeiro: Ed. Consequência.

DOZENA, A. (2017), Geografia e Música: Diálogos, Natal; Ed. UFRN.
FRYDBERG, M. (2017). Novos agentes e novas configurações no carnaval dos blocos de rua na cidade do Rio de Janeiro. In. Ponto Urbe. Revista do núcleo de antropologia urbana da USP. São Paulo, 20.

HERSCHMANN, M. (2013). Apontamentos sobre o crescimento do Carnaval de rua no Rio de Janeiro no início do século 21. In. Intercom - RBCC. São Paulo, 36(2), jul./dez.

HIJIKI, R. (2005). Etnografia da performance musical, Identidade, alteridade e transformação. Horizontes Antropológicos, Porto Alegre, ano 11(24): 155-184, jul./dez. 2005.

GALLAGHER, Michael (2016). Sound as affect: Difference, power and spatiality. Emotion, Space and Society. v. xxx, p. 1-7.

MENEZES, J. (2007). Cultura do ouvir: vínculos sonoros na contemporaneidade. XXX Congresso Brasileiro de Ciências da Comunicação. Santos, 29 ago. - 02 set. 2007.

MOREAUX, M., (2018). Geografia, Música e Sons. In. DOZENA, A., Geograficidade, Vol. 8, Número Especial.

PAIVA, D. (2017). Teorias não-representacionais na Geografia I: conceitos para uma geografia do que acontece. Revista Finisterra. 52 (107).

SAPIA, J. (2016). Carnaval de rua no Rio de Janeiro: afetos e participação política. In: pragMATIZES Revista Latino Americana de Estudos em Cultura, Rio de Janeiro, Ano 6 (11), abr./set.

SCHECHNER, R. (2002). Foreword: Fundamentals of Performance Studies. In. Nathan Stucky and Cynthia Wimmer (eds.). Teaching Performance Studies. Illinois: Southern Illinois University Press.

SNYDER, A. (2018). Critical Brass: the alternative brass movement and street carnival revival of olympic Rio de Janeiro. Dissertation for the degree of Doctor in Philosophy of Music. University of California: Berkeley.

STAVRIDES (2016). Hacia la ciudad de las umbrales, Madrid: Ed. Akal.

TURNER, V. (1987). The Anthropology of performance. New York: PAJ Publications. 


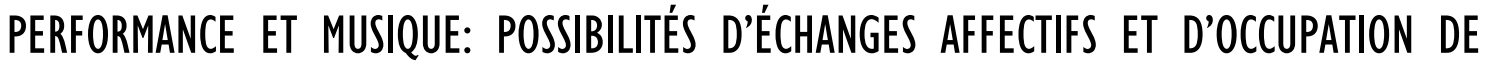 L'ESPACE PUBLIC AU FESTIVAL ACTIVISTE DE FANFARES HONK! RIO 2018}

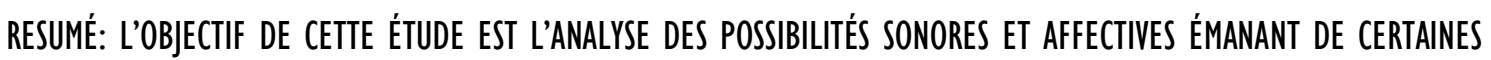
PERFORMANCES DE GROUPES dE FANFARES, QUI ONT PARTIIIPÉ DU FESTIVAL ACTIIISTE HONK! RIO EN 2018. IL S'AGIT

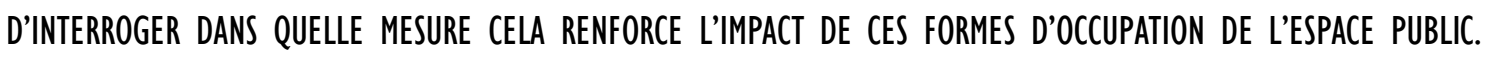
DANS CE travalL, ON SE PENCHE SUR CERTAINES PERFORMANCES QUI ONT EU LIEU DURANT L'ÉDITION 2018. LA recherche sur le terrain a Été réalisée en partenariat aVEC une anthropologue, dURANt le fEstival, et COMPORTE UNE FORTE DIMENSION ETHNOGRAPHIQUE, À traVEeRS LA COLLECTE d'OBSERVATIONS, MAIS AUSSI PARFOIS

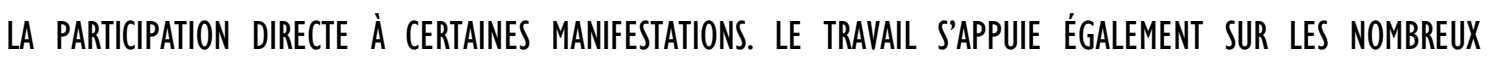
ENTRETIENS RÉalsÉS AUPRÈS dE MUSICIENS, D’ORGaNISATEURS, MEMBRES DU PUBLIC ET VENDEURS AMBULLANTS. DANS

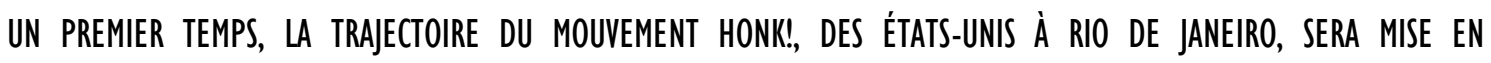

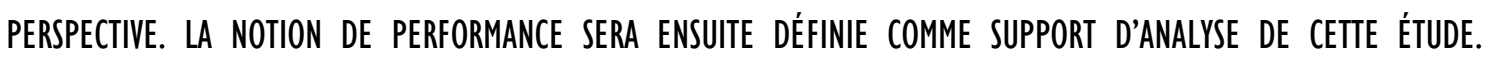

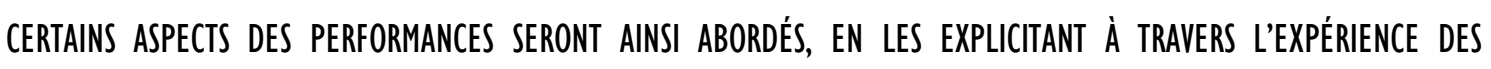

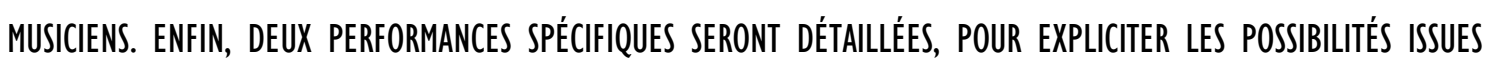
DU MÉLANGe de LANGAGES ARTISTIQUES, AINSI QU'ILLUSTRER La PERFORMANCE COMME ACTE POLLTIQUE. MOTS-CLÉ: PERFORMANCE; ESPACE PUBLLC; FANFARES.

\section{PERFORMANCE AND MUSIC: POSSIBILITIES OF AFFECTIVE EXCHANGES AND OCCUPATION OF PUBLIC SPACE AT THE BRASS BAND ACTIVIST FESTIVAL HONK! RIO 2018}

ABSTRACT: THE AIM OF THIS PAPER IS TO ANALYSE THE SOUNDS AND AFFECTIIE POSSIBLLITIES THAT EMERGED FROM SOME BRASS BAND PERFORMANCES DURING THE ACTIVIST FESTIVAL HONK! RIO IN 2018. IT IS WORTH QUESTIONING TO WHAT EXTENT tHESE PERFORMANCES PARTICIPATE IN MORE POWERFUL FORMS OF OCCUPATION OF PUBLIC SPACE. THE FOCUS OF THIS WORK IS ON THE PERFORMANCES THAT TOOK PLACE DURING THE 2018 EDITION. THE FIELDWORK, WITH AN ETHNOGRAPHIC APPROACH, WAS CARRIED OUT DURING THE FESTIVAL, BASED ON INTERVIEWS 
WITH THE PUBLIC, MUSICIANS, ORGANIZERS AND STREET VENDORS, IN ADDITION TO COLLECTING OBSERVATIONS FROM THE FIELD AND ALSO PERFORMING ALONG WITH THE ARTISTS IN SOME OCCASIONS. INITIALLY, THE TRAJECTORY OF THE HONK! MOVEMENT FROM SOMMERVILLE (UNITED STATES) TO RIO DE JANEIRO WILL BE PRESENTED, RELATING HOW THE NOTION OF PERFORMANCE IS ESTABLISHED AS AN ANALYSIS BIAS IN THIS STUDY. THEN, ASPECTS OF THE PERFORMANCES THAT TOOK PLACE AT HONK! RIO WILL BE COVERED, DISCUSSING THE EXPERIENCE OF MUSICIANS AND PARTICIPATING IN THE FESTIVAL. FINALLY, TWO SPECIFIC PERFORMANCES WILL BE PORTRAYED, IN ORDER TO EXPOSE THE POSSIBILITIES ARISING FROM THE MIXTURE OF ARTISTIC LANGUAGES AND PERFORMANCE AS A POLITICAL ACT. KEYWORDS: PERFORMANCE; PUBLIC SPACE, BRASS BANDS. 